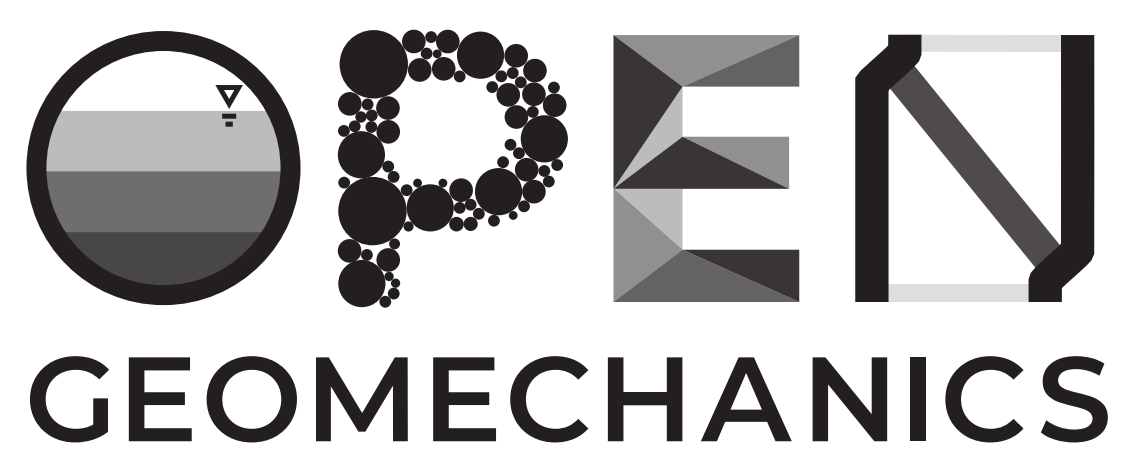

\title{
Editorial
}

\author{
Edward Andò ${ }^{*}$, Jelke Dijkstra**, David Frost***, Ivo \\ Herle $^{\dagger}$, Ryan Hurley ${ }^{\ddagger}$, Benjy Marks ${ }^{\dagger \dagger}$, David Muir \\ Wood $^{\ddagger \ddagger}$, Claudio Tamagnini ${ }^{\S}$ \& Cino Viggiani ${ }^{`}$ \\ * Université Grenoble Alpes \\ ** Chalmers University \\ *** Georgia Institute of Technology \\ † Technische Universität Dresden \\ ‡ Johns Hopkins University \\ †† The University of Sydney \\ 执 University of Bristol \\ $\$$ Università degli Studi di Perugia \\ - Université Grenoble Alpes.
}

Published

28th January 2019

https://doi.org/10.5802/ogeo.0

Correspondence

Centre Mersenne

Bâtiment CETA

150 rue de la Chimie

CS 40700

38058 Grenoble Cedex 9

France

editor@opengeomechanics.org

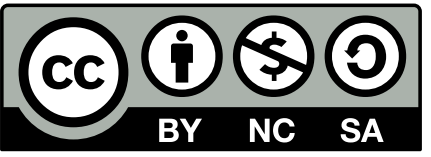

This article is licensed under the Creative Commons Attribution NonCommercial ShareAlike 4.0 License.

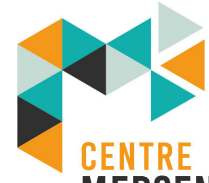

MERSENNE

Open Geomechanics is member of the Centre Mersenne for Open Scientific Publishing
This Editorial is the first publication from the journal Open Geomechanics, a radically open-access scientific journal for Geomechanics Research, edited by Geomechanics researchers for Geomechanics researchers. We believe that the results of scientific research should be available to all. For this reason, this journal is committed to publishing high quality work within the remit of diamond open access - free to publish and read. Our aim is to become a recognised journal in the field of geomechanics, and a launchpad for new ideas for the dissemination of research in this field. Research manuscripts (in any geomechanics related topics such as analytical, numerical or experimental studies) or case studies, negative results, as well as replicability or reproducibility studies are welcome. 


\section{Conflicts of Interest}

The editors maintain individual up to date conflict of interest statements directly on the Open Geomechanics website.

\section{Acknowledgements}

We would like to acknowledge the support of the Centre Mersenne for their assistance with the publication of this journal.

Manuscript received and accepted 1st January 2019. 